\title{
Rhizosphere Enzyme Activities as Influenced Chemical Weed Management Practices in the Transplanted Rice
}

\author{
P. Spandana Bhatt*, M. Yakadri, Subashreddy, M. Madhavi, S. Sridevi and Leela Rani
}

Agricultural Research Institute, PJTSAU, Hyderabad, India

*Corresponding author

\begin{tabular}{|c|}
\hline Keywords \\
\hline $\begin{array}{l}\text { Rhizosphere, Enzyme } \\
\text { activities, Chemical weed } \\
\text { management practices, } \\
\text { Transplanted rice }\end{array}$ \\
\hline Article Info \\
\hline $\begin{array}{l}\text { Accepted: } \\
16 \text { April } 2018 \\
\text { Available Online: } \\
10 \text { May } 2018\end{array}$ \\
\hline
\end{tabular}

\section{A B S T R A C T}

The activity of dehydrogenase ( $\mu \mathrm{g}$ TPF produced $\left.\mathrm{g}^{-1} \mathrm{day}^{-1}\right)$ followed decreasing trend from before treatment imposition to 3 days after treatment imposition thereafter it showed increasing trend. Sulfonyl urea herbicides had the lower dehydrogenase activity immediately after herbicide application as compared to the other herbicide group's viz., chloroacetamide, triazolepyramidine, pyramidinethiobenzole and aryloxyphenoxy propionate. Urease activity ( $\mu \mathrm{g}$ of $\mathrm{NH}_{4}{ }^{+}$released $\mathrm{g}^{-1}$ soil $2 \mathrm{hr}^{-1}$ ), increased from 0 DAT up to $45 \mathrm{DAT}$ and thereafter it decreased. There was slight initial depression in the urease activity 3 days after application in every treatment. With the progress of time by $15-20$ DAT herbicide treated plots recorded on par results with weedy check (control). Further at 23 DAT, herbicide treated plots recorded significantly higher urease activity than control during both the years of study. Activity of acid phosphatase and alkaline phosphatase ( $\mu \mathrm{g}$ of PNP released $\mathrm{g}^{-1}$ soil $\mathrm{h}^{-1}$ ) increased from 0 DAT to 45 DAT, thereafter the activity decreased. At 6 DAT and 15 DAT the higher acid phosphatase activity was recorded in weedy check $\left(\mathrm{T}_{14}\right)$ which was on par with hand weeding twice at 25 and 45 DAT $\left(\mathrm{T}_{13}\right)$. The reduction in acid phosphatase activity is in the range of $15 \%$ and $20 \%$ over control during 2013 and 2014 respectively. Detracting effect of herbicides towards enzyme activities decreased with time. Except a slight depression initially the tested herbicides at field rate was non-inhibitory for prolonged period.

\section{Introduction}

Herbicides are biologically active compounds, and an unintended consequence of its application may lead to significant changes in microbial populations and activities influencing microbial ecological balance affecting soil fertility.

The fate of herbicides applied in agricultural ecosystems is governed by the transfer and degradation processes, and their interaction with soil microorganisms. The sustainable agriculture involves optimizing agricultural resources and at the same time maintaining the quality of environment and sustaining natural resources.

In achieving this optimization, the soil microbial community composition is of great importance, because they play a crucial role in carbon flow, nutrient cycling and litter decomposition, which in turn affect soil fertility and plant growth. 
The increasing reliance of sustainable agriculture on herbicides has led to a concern about their ecotoxicological effects influencing microbial populations, which may serve as indicators of soil quality. The interaction between herbicides and soil microorganisms may be of practical significance because of possible inhibition in microbial activities contributing to soil fertility. Hence there is a need to study the effects of herbicides on soil microbial population communities and there by addressing the apprehensions about the environmental impacts of herbicide use.

\section{Materials and Methods}

The soil of the experimental site was sandy clay loam in texture, neutral in reaction, low in available nitrogen, high in available phosphorus and available potassium. The experiment was laid out in randomized block design with fourteen weed management practices T1: pretilachlor @ $625 \mathrm{~g}$ a.i. ha ${ }^{-1}$ as PE at 3 DAT, T2: pyrazosulfuron ethyl @ 20 g a.i. ha ${ }^{-1} 3$ DAT, T3: pretilachlor $6 \%+$ bensulfuron methyl 0.6\% @ $10 \mathrm{~kg}$ granules ha $^{-1}$ as PE at 3 DAT, T4: pyrazosulfuron ethyl @ $20 \mathrm{~g}$ a.i. ha ${ }^{-1}$ at 3 DAT followed by manual weeding at 25 DAT, T5: penoxsulam @ 22.5 g a.i. ha ${ }^{-1}$ as PoE at 12 DAT, T6: cyhalofop-pbutyl@100 g a.i. ha ${ }^{-1}$ as PoE 15 DAT, T7: bispyribac sodium @25 g a.i. ha ${ }^{-1}$ as PoE 25 DAT, T8: azimsulfuron @ $35 \mathrm{~g}$ a.i. ha ${ }^{-1}$ as PoE at 25 DAT, T9: bispyribac sodium @ 25 g a.i. ha ${ }^{-1}+$ ethoxysulfuron $18.75 \mathrm{~g}$ a.i. $\mathrm{ha}^{-1}$ as PoE at 25 DAT, T10: bispyribac sodium @ 20 g a.i. ha $^{-1}+$ metsulfuron methyl + chlorimuron ethyl @ $4 \mathrm{~g}$ a.i. ha ${ }^{-1}$ as PoE at 25 DAT, T11: pretilachlor@750 g a.i. ha ${ }^{-1}$ as PE at 3 DAT fbethoxysulfuron@18.75 g a.i. ha ${ }^{-1}$ as PoE at 25 DAT, T12: pretilachlor @ 750 g a.i. ha ${ }^{-1}$ as $\mathrm{PE}$ at 3 DAT fbmetsulfuron methyl + chlorimuron ethyl @ $4 \mathrm{~g}$ a.i. ha ${ }^{-1}$ as PoE at 25 DAT, T13: hand weeding twice at 25 and 45 DAT and T14: weedy check.

\section{Assay of enzyme activity}

\section{Dehydrogenase activity}

One gram of soil sample was taken in $50 \mathrm{ml}$ glass tube. Then $50 \mathrm{mg}$ of $\mathrm{CaCO}_{3}$ was added followed by $2.5 \mathrm{ml}$ of distilled water and $1 \mathrm{ml}$ of 3\% Triphenyltetrazolium chloride (TTC). Swirled for few minutes and incubated at $37^{\circ} \mathrm{C}$ for 24 hours.

The red precipitate of the Triphenylformazan (TPF) was dissolved in $10 \mathrm{ml}$ of methanol and the contents were shaken for 30 minutes, the contents were filtered into $25 \mathrm{ml}$ volumetric flask and the volume made upto $25 \mathrm{ml}$ with methanol. Intensity of red colour was measured with spectrophotometer at $485 \mathrm{~nm}$ (Casida, 1964).

\section{Urease activity}

Urease activity in soil was assayed by quantifying the ratio of release of $\mathrm{NH}_{4}{ }^{+}$from the hydrolysis of urea (Tabatabai and Bremner, 1969). $5 \mathrm{~g}$ of soil was taken in a 50 $\mathrm{ml}$ volumetric flask, after adding $0.2 \mathrm{ml}$ of toluene and $9 \mathrm{ml}$ THAM buffer, the flask was swirled for a few seconds to mix the contents and $1 \mathrm{ml}$ of $0.2 \mathrm{M}$ urea solution was added and swirled the flask again for a few seconds.

Then the flask was stoppered and placed in an incubator at $37^{\circ} \mathrm{C}$. After 2 hours, the stopper was removed, and approximately $35 \mathrm{ml}$ of $\mathrm{KCl}-\mathrm{Ag}_{2} \mathrm{SO}_{4}$ solution was added, swirled the flask for a few seconds, and allowed the flask to stand until the contents have cooled to room temperature (about $5 \mathrm{~min}$ ). The contents were made to $50 \mathrm{ml}$ by addition of $\mathrm{KCl}-\mathrm{Ag}_{2} \mathrm{SO}_{4}$ solution, the flask was stoppered and inverted several times to mix the contents. $\mathrm{NH}_{4}^{+}-\mathrm{N}$ was determined in the resulting soil suspension, by pipetting out $20 \mathrm{ml}$ aliquot of the suspension distilling with $0.2 \mathrm{~g}$ of $\mathrm{MgO}$ for $4 \mathrm{~min}$. 
Controls were performed by following the procedure described for assay of urease activity, but for the addition of $1 \mathrm{ml}$ of $0.2 \mathrm{M}$ urea solution after the addition of $\mathrm{KCl}-\mathrm{Ag}_{2} \mathrm{SO}_{4}$ solution.

\section{Phosphomonoesterase activity}

The procedure followed was of Tabatabai and Bremner (1969) for assay of acid phosphatases and Eivazi and Tabatabai (1977) for alkaline phosphatases. One gram of soil sample was taken in glass tube. Then $0.2 \mathrm{ml}$ of toluene was added followed by $4 \mathrm{ml}$ of MUB buffer $\mathrm{pH} 6.5$ (for acid phosphatase), $4 \mathrm{ml}$ MUB buffer $\mathrm{pH} 11.0$ (for alkaline phosphatase) and $1 \mathrm{ml}$ of $\mathrm{p}$ - nitro phenyl phosphate (only for samples) was added. Glass tubes swirled for few seconds, stoppered and incubated for 1 hour at $37^{\circ} \mathrm{C}$. After incubation, $1 \mathrm{ml}$ of $0.5 \mathrm{M}$ $\mathrm{CaCl}_{2} 2 \mathrm{H}_{2} \mathrm{O}$ and $4 \mathrm{ml}$ of $0.5 \mathrm{M} \mathrm{NaOH}$ was added, swirled and filtered. The intensity of yellow color was measured with spectrophotometer at $420 \mathrm{~nm}$. Controls were run simultaneously following the same procedure except adding $1 \mathrm{ml}$ of p-nitro phenyl phosphate (PNP) solution.

\section{Results and Discussion}

Soil enzyme activities have been suggested as suitable indicators of soil quality because they are a measure of soil microbial activity and are related to the nutrient cycles and transformations (Bollen, 1961). Soil enzyme activities are early and sensitive indicators to measure the degree of soil degradation in both natural and agro-ecosystems. Since they are sensitive to ecological stress and land management practices these biological parameters have been used to assess soil quality and health as affected by agricultural practices. Enzyme activity is influenced by soil conditions such as organic matter content, moisture, temperature and many other factors like chemical nature of herbicides, concentration used, microbial community structure, type of soil, and soil conditions. Herbicides reaching the soil may disturb microbial metabolism or enzyme activities (Bowles et al., 2014). Herbicides are extraneous to soil component pools and are expected to affect activities of different soil enzymes and discussed in the following sections.

\section{Dehydrogenase activity (DHA)}

Dehydrogenase activity is thought to reflect the total scope of activity of soil micro flora and is consequently a good indicator of microbial activity. It may be considered as a valuable parameter for assessing the side effects of herbicide treatments on the soil microbial biomass and can also be used as an indicator of the microbiological redox system. Dehydrogenase is an intracellular enzyme involved in microbial oxygen metabolism. This activity depends on the metabolic state of soil biota and may be a good indicator of soil microbial activity (Nannipieri et al., 2003).

The activity of dehydrogenase ( $\mu \mathrm{g}$ TPF produced $\mathrm{g}^{-1}$ day $^{-1}$ ) as influenced by the herbicide treatments is presented in Table 1 and 2. A close perusal of data during 2013 and 2014 indicates that significant difference exist between herbicide treatments. The soil DH activity showed decreasing trend up to 3 days after treatment imposition thereafter it showed increasing trend. It can be seen that DHA levels was found significantly higher in hand weeding and weedy check plots.

At 6 DAT the higher dehydrogenase activity was recorded in weedy check (5 and $5.9 \mu \mathrm{g}$ TPF produced $\mathrm{g}^{-1}$ day $^{-1}$ ) respectively in 2013 and 2014, which was on par with rest of the treatments except in treatments where PE herbicide application was done with pretilachlor in $\mathrm{T}_{1}$ (4.1 and 5.1), $\mathrm{T}_{11}$ (4.3 and 4.8), $\mathrm{T}_{12}$ (4.1 and 4.9), pyrazosulfuron ethyl in 
$\mathrm{T}_{2}$ (4.0 and 4.6), $\mathrm{T}_{4}\left(4.0\right.$ and 4.8) and $\mathrm{T}_{3}$ pretilachlor + bensulfuron methyl (3.9 and 4.9) during 2013 and 2014 respectively. Dehydrogenase activity was recovered and recorded the on par results with weedy check (control) by 15 DAT in plots of pretilachlor (in $\mathrm{T}_{1}, \mathrm{~T}_{11}, \mathrm{~T}_{12}$ ) and by 23 DAT in plots of pyrazosulfuron ethyl (in $\mathrm{T}_{2}$ and $\mathrm{T}_{4}$ ) respectively during both the years of study. $\mathrm{T}_{3}$ pretilachlor + bensulfuron methyl recorded on par results with weedy check (control) by 23 DAT during 2013 and by 15 DAT during 2014. Similarly the early PoE herbicide treatments penoxsulam $\mathrm{T}_{5}(5.4$ and 6.4) and cyhalofop $\mathrm{p}$ butyl $\mathrm{T}_{6}$ (5.5 and 6.7) when applied at 12 DAT resulted in sharp decrease in activity of dehydrogenase $\mathrm{T}_{5}$ (4.9 and 5.8) and $\mathrm{T}_{6}$ (4.9 and 5.9) up to 3 days after herbicide application (15 DAT) and thereafter showed on par results with control $\mathrm{T}_{5}$ (7.2 and 7.4) and $\mathrm{T}_{6}$ (7.2 and 7.1) at 32 DAT during 2013 and 2014 respectively.

At 25 DAT PoE treatment impositions with sulfonyl urea group of herbicides azimsulfuron $\left(\mathrm{T}_{8}\right)$, ethoxysulfuron $\left(\mathrm{T}_{9}\right.$ and $\mathrm{T}_{11}$ ), metsulfuron methyl + chlorimuron ethyl $\left(\mathrm{T}_{10}\right.$ and $\mathrm{T}_{12}$ ) and pyramidinethio benzoate group bispyribac sodium $\left(\mathrm{T}_{7}, \mathrm{~T}_{9}\right.$ and $\left.\mathrm{T}_{10}\right)$ was done. Both the groups showed decreased activity of dehydrogenase at 3 days after herbicide application (28 DAT) and at later stages DHA increased significantly at 45 and 60 DAT during both the years. It is evident from the data that the soil treated with sulfonyl urea herbicides $\left(\mathrm{T}_{2}, \mathrm{~T}_{3}, \mathrm{~T}_{4}, \mathrm{~T}_{8}, \mathrm{~T}_{9}, \mathrm{~T}_{10}, \mathrm{~T}_{11}\right.$, $\mathrm{T}_{12}$ ) had the lower dehydrogenase activity immediately after herbicide application as compared to the other herbicide group treated soils but later it increased and recorded higher dehydrogenase activity than the weedy check (control).

The data suggested that the detracting effect of herbicides towards soil enzyme activities decreased with time. This is because of the recovery of microbial populations and enzyme activities after initial inhibition due to microbial adaptation to these herbicides or due to their degradation. Besides, it might be due to the microbial multiplication on increased supply of nutrients available in the forms of microorganisms killed by the herbicides (Latha and Gopal, 2010).

Besides the herbicides used at recommended rate were non-inhibitory on dehydrogenase activity (Rao and Raman, 1998). Increased enzyme activity with one hand weeding in $\mathrm{T}_{4}$ and two hand weedings in $\mathrm{T}_{13}$ might be due to increased soil aeration there by increased microorganisms and enzyme activity. (Kavitha et al., 2011). The increase in soil dehydrogenase activity in herbicides treated soil from $20^{\text {th }}$ day after application might be due to the increase in microbial community composition with the capability of utilizing the herbicides as carbon source (Sebiomo et al., 2011).

\section{Urease activity (UA)}

Urease activity in soil originates predominantly from microorganisms and is correlated with the soil organic matter content. Urease perhaps attracted a good deal of attention due, in part, to the increasing agricultural importance of its substrate, urea. Urease activity is a useful indicator to evaluate the soil pollution situation. A close perusal of data on urease activity ( $\mu \mathrm{g}$ of $\mathrm{NH}_{4}{ }^{+}$released $\mathrm{g}^{-1}$ soil $2 \mathrm{hr}^{-1}$ ) indicated that significant differences exist between herbicide treatments (Table 3 and 4). Urease activity increased up to $45 \mathrm{DAT}$ and thereafter it decreased.

At 6 DAT the higher urease activity was recorded in weedy check (58.3) during 2013 and $\mathrm{T}_{7}$ (60.7) in 2014 respectively, which was on par with rest of the treatments, except in treatments where PE herbicide application was done with pretilachlor in $\mathrm{T}_{1}$ (40.7 and 40.1), 
$\mathrm{T}_{11}$ (42.2 and 46.2), $\mathrm{T}_{12}$ (40.8 and 44.0), pyrazosulfuron ethyl in $\mathrm{T}_{2}$ (38.5 and 40.2), $\mathrm{T}_{4}$ (38.5 and 38.6) and $\mathrm{T}_{3}$ pretilachlor + bensulfuron methyl (31.7 and 35.7) during 2013 and 2014 respectively. With the progress of time by 15 DAT, the PE herbicide treated plots recorded on par results with weedy check (control). Further at 23 DAT, herbicide treated plots recorded significantly higher urease activity than control during both the years of study.

In the same way early PoE herbicide treatments penoxsulam $\mathrm{T}_{5}(72.4$ and 71.3$)$ and cyhalofop p butyl $\mathrm{T}_{6}$ (69.1 and 73.0) when applied at 12 DAT resulted in sharp decrease in activity of UA at 3 days after herbicide application (15 DAT) of penoxsulam $\mathrm{T}_{5}(66.7$ and 68.5) and cyhalofop p butyl $\mathrm{T}_{6}(67.7$ and $60.5)$ and recovered by 25 DAT registering on par urease activity in $\mathrm{T}_{5}$ (78.7 and 104.3) and cyhalofop p butyl $\mathrm{T}_{6}$ (80.7 and 107.6) that of control during 2013 and 2014. From 28 DAT urease activity in $\mathrm{T}_{5}$ penoxsulam and $\mathrm{T}_{6}$ cyhalofop $\mathrm{p}$ butyl plots were more than the control plot.

At 25 DAT PoE treatments imposition with azimsulfuron $\left(\mathrm{T}_{8}\right)$, ethoxysulfuron $\left(\mathrm{T}_{9}\right.$ and $\mathrm{T}_{11}$ ), metsulfuron methyl + chlorimuron ethyl $\left(\mathrm{T}_{10}\right.$ and $\left.\mathrm{T}_{12}\right)$ and bispyribac sodium $\left(\mathrm{T}_{7}, \mathrm{~T}_{9}\right.$ and $\mathrm{T}_{10}$ ) was done, resulted in decrease in activity of urease from 3 days after herbicide application (28 DAT) and then significantly increased at later stages by 45 DAT and it was found to be decreased at 60 DAT in all the plots during both the years.

Application of herbicides disturbed the biological equilibrium in the soil, so at the initial stages of herbicidal application lower the microbial population and hence enzyme activity. The tapering of inhibitory effect of soil urease activity with time and recovery during later stages may be due to different reasons viz., microbial population get stabilized after some time, the herbicides themselves are adsorbed increasingly irreversibly on soil colloids with progress of time and this may result in decreased inhibition. The partial degradation of these herbicides with time in soil is also another factor for decrease in inhibition. These results were in agreement with Kavitha et al., (2011).It is reported that herbicides gets adsorbed by organic soil amendments to form the bound or recalcitrant states, which in turn reduces, the possibility of microbial attack might also count for the insignificant effect or masking of herbicide impact on the activity of enzymes (Perucci et al., 2000).

At later stages urease activity in herbicide treated plots was more than control may be due to microbial multiplication on increased supply of nutrients available in the form of weeds killed by herbicides (Latha and Gopal, 2010).

The addition of herbicide might have provided substrate of urease in soil only initially which soon thereafter got hydrolyzed to ammonium carbonate thus leading to paucity of the substrate and this might be the reason for the decreased urease activity after 45 DAT.

\section{Phosphomonoesterases}

Phosphatases are extra cellular enzymes produced by many soil microorganisms and are responsible for the hydrolysis of organic $\mathrm{P}$ compounds to inorganic P. Phosphatases represent a broad range of intracellular as well as soil accumulated activities that catalyse the hydrolysis of both the esters and anhydrides of phosphoric acid. Phosphatase is concentrated in the surface layer and rhizosphere where most of the fresh and less humified organic matter is prevailing. Phosphatases play a crucial role in the phosphorous acquisition of plants and microorganisms, and thus in the cycling of $\mathrm{P}$ within the soil. 
Table.1 Soil dehydrogenase activity ( $\mu \mathrm{g}$ TPF produced $\mathrm{g}^{-1}$ day ${ }^{-1}$ ) as influenced by weed management practices (2013)

\begin{tabular}{|c|c|c|c|c|c|c|c|c|c|c|c|}
\hline S. No & Treatments & $\begin{array}{c}0 \\
\text { DAT }\end{array}$ & $\begin{array}{c}6 \\
\text { DAT }\end{array}$ & $\begin{array}{c}12 \\
\text { DAT }\end{array}$ & $\begin{array}{c}15 \\
\text { DAT }\end{array}$ & $\begin{array}{c}23 \\
\text { DAT }\end{array}$ & $\begin{array}{l}25 \\
\text { DAT }\end{array}$ & $\begin{array}{c}28 \\
\text { DAT }\end{array}$ & $\begin{array}{c}32 \\
\text { DAT }\end{array}$ & $\begin{array}{c}45 \\
\text { DAT }\end{array}$ & $\begin{array}{c}60 \\
\text { DAT }\end{array}$ \\
\hline $\mathbf{T}_{1}$ & Pretilachlor@625 g a.i ha ${ }^{-1}$ as PE at 3 DAT & 4.4 & 4.1 & 5.3 & 6.4 & 6.9 & 7.1 & 7.4 & 8.6 & 9.7 & 10.7 \\
\hline $\mathbf{T}_{2}$ & Pyrazosulfuron ethyl @ $20 \mathrm{~g}$ a.i ha ${ }^{-1} 3$ DAT & 4.4 & 4.0 & 4.5 & 5.1 & 6.6 & 7.0 & 7.3 & 8.6 & 9.9 & 10.8 \\
\hline$\overline{T_{3}}$ & $\begin{array}{l}\text { Pretilachlor } 6 \%+\text { bensulfuron methyl } 0.6 \% @ 10 \mathrm{~kg} \\
\text { granules ha }{ }^{-1} \text { as PE at } 3 \text { DAT }\end{array}$ & 4.4 & 3.9 & 4.6 & 5.2 & 6.8 & 7.1 & 7.3 & 8.8 & 10.3 & 10.9 \\
\hline $\mathbf{T}_{4}$ & $\begin{array}{l}\text { Pyrazosulfuron ethyl @ } 20 \mathrm{~g} \text { a.i ha }{ }^{-1} \text { at } 3 \text { DAT followed } \\
\text { by } \\
\text { manual weeding at } 25 \text { DAT }\end{array}$ & 4.4 & 4.0 & 4.7 & 5.4 & 6.8 & 7.0 & 7.5 & 8.8 & 10.1 & 10.7 \\
\hline $\mathbf{T}_{\mathbf{5}}$ & Penoxsulam @22.5 g a.i ha ${ }^{-1}$ as early PoE at 12 DAT & 4.4 & 4.6 & 5.4 & 4.9 & 5.8 & 6.1 & 7.2 & 8.6 & 10.2 & 10.7 \\
\hline $\mathrm{T}_{6}$ & $\begin{array}{l}\text { Cyhalofop-p-butyl @ } 100 \mathrm{~g} \text { a.i ha }{ }^{-1} \text { as early PoE } 12 \\
\text { DAT }\end{array}$ & 4.4 & 4.8 & 5.5 & 4.9 & 5.9 & 6.1 & 7.2 & 8.6 & 9.8 & 10.8 \\
\hline $\mathbf{T}_{7}$ & Bispyribac sodium @ $25 \mathrm{~g}$ a.i ha ${ }^{-1}$ as PoE 25 DAT & 4.4 & 4.7 & 5.4 & 6.0 & 6.6 & 7.3 & 6.0 & 7.7 & 9.7 & 10.7 \\
\hline $\mathbf{T}_{8}$ & Azimsulfuron@35 g a.i ha ${ }^{-1}$ as PoE at $25 \mathrm{DAT}$ & 4.4 & 4.5 & 5.4 & 6.2 & 6.6 & 7.0 & 5.7 & 7.1 & 8.6 & 11.0 \\
\hline$\overline{T_{9}}$ & $\begin{array}{l}\text { Bispyribac sodium @ } 25 \mathrm{~g} \mathrm{a.i} \mathrm{ha}{ }^{-1}+\text { ethoxysulfuron } \\
18.75 \mathrm{~g} \mathrm{a.i} \mathrm{ha}^{-1} \text { as PoE at } 25 \mathrm{DAT}\end{array}$ & 4.4 & 4.7 & 5.6 & 6.3 & 6.8 & 7.1 & 5.6 & 7.1 & 8.4 & 10.7 \\
\hline $\mathbf{T}_{10}$ & $\begin{array}{l}\text { Bispyribac sodium @ } 20 \mathrm{~g} \text { a.i ha }{ }^{-1}+\text { metsulfuron methyl } \\
+ \\
\text { chlorimuron ethyl @ } 4 \mathrm{~g} \mathrm{a.i} \mathrm{ha-1} \text { as PoE at } 25 \text { DAT }\end{array}$ & 4.4 & 4.7 & 5.7 & 6.4 & 6.7 & 7.2 & 6.0 & 7.3 & 8.9 & 10.9 \\
\hline $\mathbf{T}_{11}$ & $\begin{array}{l}\text { Pretilachlor@ } 950 \mathrm{~g} \text { a.i ha }{ }^{-1} \text { as PE at } 3 \text { DAT followed } \\
\text { by } \\
\text { ethoxysulfuron@ } 18.75 \mathrm{~g} \mathrm{a} . \mathrm{ha}^{-1} \text { as PoE at } 25 \mathrm{DAT}\end{array}$ & 4.4 & 4.3 & 5.5 & 6.5 & 6.9 & 7.3 & 6.0 & 7.2 & 8.7 & 11.0 \\
\hline $\mathbf{T}_{12}$ & $\begin{array}{l}\text { Pretilachlor @ } 750 \mathrm{~g} \text { a.i ha }{ }^{-1} \text { as PE at } 3 \text { DAT followed } \\
\text { by } \\
\text { metsulfuron methyl + chlorimuron ethyl @ } 4 \mathrm{~g} \text { a.i ha }{ }^{-1} \\
\text { as PoE at } 25 \text { DAT }\end{array}$ & 4.4 & 4.1 & 5.4 & 6.6 & 7.0 & 7.4 & 6.0 & 7.6 & 9.9 & 11.1 \\
\hline $\mathbf{T}_{13}$ & Hand weeding twice at 25 and 45 DAT & 4.4 & 4.7 & 5.9 & 6.5 & 6.8 & 7.2 & 7.5 & 9.1 & 10.3 & 11.2 \\
\hline $\mathbf{T}_{14}$ & weedy check & 4.4 & 5.0 & 5.9 & 6.5 & 7.0 & 7.3 & 7.5 & 8.5 & 9.6 & 9.9 \\
\hline & $\mathrm{SEm} \pm$ & - & 0.2 & 0.2 & 0.2 & 0.2 & 0.2 & 0.1 & 0.2 & 0.2 & 0.1 \\
\hline & $\mathrm{CD}(\mathrm{P}=0.05)$ & - & 0.5 & 0.6 & 0.7 & 0.5 & 0.4 & 0.4 & 0.6 & 0.6 & 0.5 \\
\hline
\end{tabular}


Table.2 Soil dehydrogenase activity ( $\mu \mathrm{g}$ TPF produced $\mathrm{g}^{-1}$ day $^{-1}$ ) as influenced by weed management practices (2014)

\begin{tabular}{|c|c|c|c|c|c|c|c|c|c|c|c|}
\hline S. No & Treatments & $\begin{array}{c}\text { 0 } \\
\text { DAT }\end{array}$ & $\begin{array}{c}6 \\
\text { DAT }\end{array}$ & $\begin{array}{c}12 \\
\text { DAT }\end{array}$ & $\begin{array}{c}15 \\
\text { DAT }\end{array}$ & $\begin{array}{c}23 \\
\text { DAT }\end{array}$ & $\begin{array}{c}25 \\
\text { DAT }\end{array}$ & $\begin{array}{c}28 \\
\text { DAT }\end{array}$ & $\begin{array}{c}32 \\
\text { DAT }\end{array}$ & $\begin{array}{c}45 \\
\text { DAT }\end{array}$ & $\begin{array}{c}60 \\
\text { DAT }\end{array}$ \\
\hline $\mathbf{T}_{1}$ & Pretilachlor@625 g a.i ha ${ }^{-1}$ as PE at 3 DAT & 5.1 & 5.1 & 6.4 & 6.8 & 7.1 & 7.5 & 7.6 & 8.5 & 9.9 & 10.6 \\
\hline $\mathbf{T}_{2}$ & Pyrazosulfuron ethyl @ $20 \mathrm{~g} \mathrm{a.i} \mathrm{ha}^{-1} 3$ DAT & 5.1 & 4.6 & 5.2 & 6.8 & 7.1 & 7.4 & 7.8 & 8.8 & 9.8 & 10.5 \\
\hline $\mathbf{T}_{\mathbf{3}}$ & $\begin{array}{l}\text { Pretilachlor } 6 \%+\text { bensulfuron methyl } 0.6 \% @ 10 \mathrm{~kg} \\
\text { granules } \mathrm{ha}^{-1} \text { as PE at } 3 \text { DAT }\end{array}$ & 5.1 & 4.9 & 5.3 & 6.7 & 7.2 & 7.4 & 7.6 & 8.8 & 10.2 & 10.6 \\
\hline$\overline{T_{4}}$ & $\begin{array}{l}\text { Pyrazosulfuron ethyl @ } 20 \mathrm{~g} \text { a.i ha }{ }^{-1} \text { at } 3 \text { DAT } \\
\text { followed by } \\
\text { manual weeding at } 25 \text { DAT }\end{array}$ & 5.1 & 4.8 & 5.6 & 7.0 & 7.0 & 7.6 & 7.9 & 8.9 & 10.3 & 10.6 \\
\hline $\mathbf{T}_{5}$ & Penoxsulam@22.5 g a.i ha ${ }^{-1}$ as early PoE at 12 DAT & 5.1 & 5.5 & 6.4 & 5.8 & 6.1 & 6.9 & 7.4 & 8.4 & 10.3 & 10.5 \\
\hline$T_{6}$ & $\begin{array}{l}\text { Cyhalofop-p-butyl@100 g a.i ha }{ }^{-1} \text { as early PoE } 12 \\
\text { DAT }\end{array}$ & 5.1 & 5.6 & 6.7 & 5.9 & 6.2 & 6.6 & 7.1 & 8.9 & 9.8 & 10.8 \\
\hline$\overline{\mathbf{T}_{7}}$ & Bispyribac sodium @ $25 \mathrm{~g}$ a.i ha ${ }^{-1}$ as PoE 25 DAT & 5.1 & 5.6 & 6.2 & 6.7 & 7.3 & 7.7 & 6.3 & 7.4 & 9.7 & 10.7 \\
\hline$\overline{T_{8}}$ & Azimsulfuron@35 g a.i ha ${ }^{-1}$ as PoE at 25 DAT & 5.1 & 5.6 & 6.3 & 6.8 & 7.1 & 7.4 & 6.5 & 7.4 & 8.7 & 10.7 \\
\hline$T_{9}$ & $\begin{array}{l}\text { Bispyribac sodium @ } 25 \mathrm{~g} \mathrm{a} . \mathrm{i} \mathrm{ha}^{-1}+\text { ethoxysulfuron } \\
18.75 \mathrm{~g} \mathrm{a} . \mathrm{i} \mathrm{ha} \mathrm{H}^{-1} \text { as PoE at } 25 \mathrm{DAT}\end{array}$ & 5.1 & 5.7 & 6.4 & 6.8 & 7.3 & 7.6 & 6.3 & 7.5 & 9.4 & 10.5 \\
\hline $\mathbf{T}_{10}$ & $\begin{array}{l}\text { Bispyribac sodium @ } 20 \mathrm{~g} \text { a.i ha } \mathrm{ha}^{-1}+\text { metsulfuron } \\
\text { methyl + } \\
\text { chlorimuron ethyl @ } 4 \mathrm{~g} \text { a.i ha }{ }^{-1} \text { as PoE at } 25 \text { DAT }\end{array}$ & 5.1 & 5.8 & 6.5 & 6.8 & 7.3 & 7.5 & 6.1 & 7.9 & 9.2 & 10.7 \\
\hline $\mathbf{T}_{11}$ & $\begin{array}{l}\text { Pretilachlor@750 g a.i ha }{ }^{-1} \text { as PE at } 3 \text { DAT followed } \\
\text { by } \\
\text { ethoxysulfuron@18.75 g a.i ha }{ }^{-1} \text { as PoE at } 25 \text { DAT }\end{array}$ & 5.1 & 4.8 & 6.6 & 7.1 & 7.3 & 7.7 & 6.1 & 7.6 & 9.1 & 10.7 \\
\hline $\mathbf{T}_{12}$ & $\begin{array}{l}\text { Pretilachlor @ } 750 \mathrm{~g} \text { a.i ha }{ }^{-1} \text { as PE at } 3 \text { DAT followed } \\
\text { by } \\
\text { metsulfuron methyl + chlorimuron ethyl @ } 4 \mathrm{~g} \text { a.i ha }{ }^{-1} \\
\text { as PoE at } 25 \text { DAT }\end{array}$ & 5.1 & 4.9 & 6.7 & 7.2 & 7.5 & 7.8 & 6.1 & 7.6 & 9.8 & 10.7 \\
\hline $\mathbf{T}_{13}$ & Hand weeding twice at 25 and 45 DAT & 5.1 & 6.0 & 6.4 & 7.0 & 7.3 & 7.6 & 7.8 & 8.8 & 10.5 & 10.8 \\
\hline \multirow[t]{3}{*}{$\mathbf{T}_{14}$} & weedy check & 5.1 & 5.9 & 6.5 & 7.1 & 7.4 & 7.6 & 7.9 & 8.9 & 10.3 & 10.6 \\
\hline & $\mathrm{SEm} \pm$ & - & 0.2 & 0.2 & 0.2 & 0.2 & 0.2 & 0.3 & 0.2 & 0.2 & 0.1 \\
\hline & $\mathrm{CD}(\mathrm{P}=0.05)$ & - & 0.5 & 0.7 & 0.5 & 0.5 & 0.5 & 0.9 & 0.6 & 0.6 & 0.3 \\
\hline
\end{tabular}


Table.3 Urease activity ( $\mu \mathrm{g}$ of $\mathrm{NH}_{4}{ }^{+}$released $\mathrm{g}^{-1}$ soil $2 \mathrm{hr}^{-1}$ ) as influenced by weed management practices (2013)

\begin{tabular}{|c|c|c|c|c|c|c|c|c|c|c|c|}
\hline S.No & Treatments & $\begin{array}{c}0 \\
\text { DAT }\end{array}$ & $\begin{array}{c}6 \\
\text { DAT }\end{array}$ & $\begin{array}{c}12 \\
\text { DAT }\end{array}$ & $\begin{array}{c}15 \\
\text { DAT }\end{array}$ & $\begin{array}{c}23 \\
\text { DAT }\end{array}$ & $\begin{array}{c}25 \\
\text { DAT }\end{array}$ & $\begin{array}{c}28 \\
\text { DAT }\end{array}$ & $\begin{array}{c}32 \\
\text { DAT }\end{array}$ & $\begin{array}{c}45 \\
\text { DAT }\end{array}$ & $\begin{array}{c}60 \\
\text { DAT }\end{array}$ \\
\hline $\mathbf{T}_{1}$ & Pretilachlor@625 g a.i ha ${ }^{-1}$ as PE at 3 DAT & 45.1 & 40.7 & 66.5 & 76.6 & 82.0 & 82.7 & 87.3 & 106.8 & 121.0 & 96.1 \\
\hline $\mathbf{T}_{2}$ & Pyrazosulfuron ethyl @ $20 \mathrm{~g}$ a.i ha ${ }^{-1} 3$ DAT & 45.1 & 38.5 & 67.7 & 80.9 & 86.7 & 89.1 & 91.2 & 111.5 & 142.3 & 100.3 \\
\hline $\mathbf{T}_{3}$ & $\begin{array}{l}\text { Pretilachlor } 6 \%+\text { bensulfuron methyl } 0.6 \% @ 10 \mathrm{~kg} \\
\text { granules ha }{ }^{-1} \text { as PE at } 3 \text { DAT }\end{array}$ & 45.1 & 31.7 & 61.8 & 76.8 & 82.9 & 85.3 & 88.5 & 101.5 & 133.0 & 97.6 \\
\hline $\mathbf{T}_{4}$ & $\begin{array}{l}\text { Pyrazosulfuron ethyl @ } 20 \mathrm{~g} \text { a.i ha }{ }^{-1} \text { at } 3 \text { DAT } \\
\text { followed by } \\
\text { manual weeding at } 25 \text { DAT }\end{array}$ & 45.1 & 38.5 & 64.2 & 78.0 & 84.1 & 86.9 & 89.3 & 116.0 & 146.4 & 110.1 \\
\hline $\mathbf{T}_{5}$ & Penoxsulam@22.5 g a.i ha ${ }^{-1}$ as early PoE at 12 DAT & 45.1 & 49.8 & 72.4 & 66.7 & 75.6 & 78.7 & 84.9 & 103.2 & 119.3 & 106.2 \\
\hline $\mathrm{T}_{6}$ & $\begin{array}{l}\text { Cyhalofop-p-butyl @ } 100 \mathrm{~g} \mathrm{a.i} \mathrm{ha}{ }^{-1} \text { as early PoE } 12 \\
\text { DAT }\end{array}$ & 45.1 & 55.0 & 69.1 & 67.7 & 76.6 & 80.7 & 85.4 & 103.8 & 116.0 & 103.1 \\
\hline $\mathbf{T}_{7}$ & Bispyribac sodium @ $25 \mathrm{~g}$ a.i ha ${ }^{-1}$ as PoE 25 DAT & 45.1 & 53.7 & 71.8 & 70.3 & 73.9 & 82.7 & 78.9 & 99.7 & 110.0 & 87.1 \\
\hline$\overline{T_{8}}$ & Azimsulfuron@35 g a.i ha ${ }^{-1}$ as PoE at 25 DAT & 45.1 & 52.5 & 70.2 & 69.8 & 75.4 & 84.5 & 73.3 & 93.8 & 120.0 & 90.2 \\
\hline $\mathbf{T}_{9}$ & $\begin{array}{l}\text { Bispyribac sodium @ } 25 \mathrm{~g} \text { a. } \mathrm{ha}^{-1}+\text { ethoxysulfuron } \\
18.75 \mathrm{~g} \mathrm{a.i} \mathrm{ha}^{-1} \text { as PoE at } 25 \mathrm{DAT}\end{array}$ & 45.1 & 52.4 & 70.7 & 73.1 & 78.9 & 81.6 & 76.9 & 100.3 & 124.0 & 101.5 \\
\hline $\mathbf{T}_{10}$ & $\begin{array}{l}\text { Bispyribac sodium @ } 20 \mathrm{~g} \text { a.i ha }{ }^{-1}+\text { metsulfuron } \\
\text { methyl + } \\
\text { chlorimuron ethyl @ } 4 \mathrm{~g} \mathrm{a.i} \mathrm{ha}{ }^{-1} \text { as PoE at } 25 \text { DAT }\end{array}$ & 45.1 & 50.2 & 73.3 & 73.3 & 79.1 & 82.5 & 74.8 & 91.5 & 113.0 & 85.5 \\
\hline $\mathbf{T}_{11}$ & $\begin{array}{l}\text { Pretilachlor@750 g a.i ha }{ }^{-1} \text { as PE at } 3 \text { DAT followed } \\
\text { by } \\
\text { ethoxysulfuron@18.75 g a.i ha }{ }^{-1} \text { as PoE at } 25 \text { DAT }\end{array}$ & 45.1 & 42.2 & 68.3 & 76.9 & 83.0 & 85.8 & 80.7 & 91.8 & 114.5 & 96.6 \\
\hline $\mathbf{T}_{12}$ & $\begin{array}{l}\text { Pretilachlor @ } 750 \mathrm{~g} \text { a.i ha }{ }^{-1} \text { as PE at } 3 \text { DAT followed } \\
\text { by } \\
\text { metsulfuron methyl + chlorimuron ethyl @ } 4 \mathrm{~g} \mathrm{a} . \mathrm{i} \mathrm{ha}{ }^{-1} \\
\text { as PoE at } 25 \mathrm{DAT}\end{array}$ & 45.1 & 40.8 & 66.5 & 80.2 & 86.6 & 89.1 & 79.9 & 93.3 & 117.2 & 96.1 \\
\hline $\mathbf{T}_{13}$ & Hand weeding twice at 25 and 45 DAT & 45.1 & 58.3 & 74.0 & 73.8 & 79.6 & 84.1 & 89.5 & 107.0 & 139.2 & 105.0 \\
\hline $\mathbf{T}_{14}$ & weedy check & 45.1 & 59.5 & 78.0 & 73.5 & 81.5 & 83.2 & 87.5 & 104.4 & 125.6 & 107.3 \\
\hline & $\mathrm{SEm} \pm$ & - & 3.9 & 6.4 & 1.6 & 1.8 & 1.6 & 4.8 & 4.7 & 8.0 & 8.6 \\
\hline & $\mathrm{CD}(\mathrm{P}=0.05)$ & - & 11.4 & N.S. & 4.6 & 5.8 & 7.6 & 10.1 & 13.6 & N.S. & N.S. \\
\hline
\end{tabular}


Table.4 Urease activity ( $\mu \mathrm{g}$ of $\mathrm{NH}_{4}{ }^{+}$released $\mathrm{g}^{-1}$ soil $2 \mathrm{hr}^{-1}$ ) as influenced by weed management practices (2014)

\begin{tabular}{|c|c|c|c|c|c|c|c|c|c|c|c|}
\hline S.No & Treatments & $\begin{array}{c}0 \\
\text { DAT }\end{array}$ & $\begin{array}{c}6 \\
\text { DAT }\end{array}$ & $\begin{array}{c}12 \\
\text { DAT }\end{array}$ & $\begin{array}{c}15 \\
\text { DAT }\end{array}$ & $\begin{array}{c}23 \\
\text { DAT }\end{array}$ & $\begin{array}{c}25 \\
\text { DAT }\end{array}$ & $\begin{array}{c}28 \\
\text { DAT }\end{array}$ & $\begin{array}{c}32 \\
\text { DAT }\end{array}$ & $\begin{array}{c}45 \\
\text { DAT }\end{array}$ & $\begin{array}{c}60 \\
\text { DAT }\end{array}$ \\
\hline $\mathbf{T}_{1}$ & Pretilachlor@625 g a.i ha ${ }^{-1}$ as PE at 3 DAT & 40.6 & 40.1 & 64.7 & 81.5 & 101.5 & 110.5 & 117.9 & 131.0 & 148.1 & 127.0 \\
\hline $\mathbf{T}_{2}$ & Pyrazosulfuron ethyl @ $20 \mathrm{~g} \mathrm{a.i} \mathrm{ha}^{-1} 3$ DAT & 40.6 & 40.2 & 62.5 & 82.3 & 97.1 & 107.6 & 118.2 & 130.5 & 145.5 & 123.1 \\
\hline $\mathbf{T}_{\mathbf{3}}$ & $\begin{array}{l}\text { Pretilachlor } 6 \%+\text { bensulfuron methyl } 0.6 \% @ 10 \mathrm{~kg} \\
\text { granules ha }{ }^{-1} \text { as PE at } 3 \text { DAT }\end{array}$ & 40.6 & 35.7 & 67.4 & 81.2 & 98.0 & 109.8 & 125.3 & 135.4 & 144.8 & 123.7 \\
\hline $\mathbf{T}_{4}$ & $\begin{array}{l}\text { Pyrazosulfuron ethyl @ } 20 \mathrm{~g} \text { a.i ha }{ }^{-1} \text { at } 3 \text { DAT } \\
\text { followed by } \\
\text { manual weeding at } 25 \text { DAT }\end{array}$ & 40.6 & 38.6 & 65.8 & 81.3 & 101.5 & 108.3 & 115.4 & 128.2 & 148.1 & 125.5 \\
\hline $\mathbf{T}_{5}$ & Penoxsulam@22.5 g a.i ha ${ }^{-1}$ as early PoE at 12 DAT & 40.6 & 54.6 & 71.3 & 68.5 & 89.3 & 104.3 & 117.1 & 133.9 & 146.3 & 116.9 \\
\hline $\mathrm{T}_{6}$ & $\begin{array}{l}\text { Cyhalofop-p-butyl @ } 100 \mathrm{~g} \text { a.i ha }{ }^{-1} \text { as early PoE } 12 \\
\text { DAT }\end{array}$ & 40.6 & 56.3 & 73.0 & 60.5 & 88.3 & 107.6 & 120.0 & 129.0 & 145.4 & 119.9 \\
\hline $\mathbf{T}_{7}$ & Bispyribac sodium @ $25 \mathrm{~g}$ a.i ha ${ }^{-1}$ as PoE 25 DAT & 40.6 & 60.7 & 71.4 & 79.0 & 83.5 & 98.0 & 90.5 & 109.5 & 136.3 & 116.8 \\
\hline$T_{8}$ & Azimsulfuron@35 g a.i ha ${ }^{-1}$ as PoE at 25 DAT & 40.6 & 54.5 & 73.8 & 76.0 & 85.2 & 96.3 & 79.2 & 105.6 & 138.0 & 112.0 \\
\hline $\mathbf{T}_{9}$ & $\begin{array}{l}\text { Bispyribac sodium @ } 25 \mathrm{~g} \mathrm{a} . \mathrm{i} \mathrm{ha}^{-1}+\text { ethoxysulfuron } \\
18.75 \mathrm{~g} \mathrm{a.i} \mathrm{ha}^{-1} \text { as PoE at } 25 \mathrm{DAT}\end{array}$ & 40.6 & 54.4 & 70.5 & 77.9 & 83.2 & 97.9 & 83.6 & 108.0 & 131.2 & 115.4 \\
\hline $\mathbf{T}_{10}$ & $\begin{array}{l}\text { Bispyribac sodium @20 g a.i ha }{ }^{-1}+\text { metsulfuron } \\
\text { methyl + } \\
\text { chlorimuron ethyl @ } 4 \mathrm{~g} \mathrm{a.i} \mathrm{ha}{ }^{-1} \text { as PoE at } 25 \mathrm{DAT}\end{array}$ & 40.6 & 57.1 & 70.8 & 78.3 & 84.1 & 94.6 & 83.5 & 108.9 & 136.6 & 115.6 \\
\hline $\mathbf{T}_{11}$ & $\begin{array}{l}\text { Pretilachlor@ } 950 \mathrm{~g} \mathrm{a.i} \mathrm{ha}{ }^{-1} \text { as PE at } 3 \text { DAT followed } \\
\text { by } \\
\text { ethoxysulfuron@18.75 g a.i ha }{ }^{-1} \text { as PoE at } 25 \text { DAT }\end{array}$ & 40.6 & 46.2 & 62.5 & 87.1 & 100.6 & 109.9 & 88.6 & 111.0 & 134.2 & 117.1 \\
\hline$T_{12}$ & $\begin{array}{l}\text { Pretilachlor @ } 750 \mathrm{~g} \text { a.i ha }{ }^{-1} \text { as PE at } 3 \text { DAT followed } \\
\text { by } \\
\text { metsulfuron methyl + chlorimuron ethyl @ } 4 \mathrm{~g} \mathrm{a.i} \mathrm{ha}^{-1} \\
\text { as PoE at } 25 \mathrm{DAT}\end{array}$ & 40.6 & 44.0 & 62.5 & 81.3 & 101.5 & 107.1 & 85.6 & 107.4 & 131.9 & 116.8 \\
\hline$T_{13}$ & Hand weeding twice at 25 and 45 DAT & 40.6 & 60.5 & 71.9 & 77.3 & 82.3 & 91.4 & 106.3 & 120.9 & 141.9 & 126.3 \\
\hline$T_{14}$ & weedy check & 40.6 & 56.3 & 70.6 & 79.4 & 81.5 & 92.4 & 107.6 & 121.9 & 140.6 & 127.5 \\
\hline & $\mathrm{SEm} \pm$ & - & 3.2 & 1.5 & 2.2 & 1.4 & 1.9 & 4.6 & 2.6 & 4.0 & 4.0 \\
\hline & $\mathrm{CD}(\mathrm{P}=0.05)$ & - & 9.4 & 4.3 & 6.5 & 4.1 & 6.5 & 13.3 & 7.5 & 17.7 & 11.6 \\
\hline
\end{tabular}


Table.5 Activity of acid phosphatase ( $\mu \mathrm{g}$ of PNP released $\mathrm{g}^{-1}$ soil $\mathrm{h}^{-1}$ ) as influenced by weed management practices (2013)

\begin{tabular}{|c|c|c|c|c|c|c|c|c|c|c|c|}
\hline S.No & Treatments & $\begin{array}{c}0 \\
\text { DAT }\end{array}$ & $\begin{array}{c}6 \\
\text { DAT }\end{array}$ & $\begin{array}{c}12 \\
\text { DAT }\end{array}$ & $\begin{array}{c}15 \\
\text { DAT }\end{array}$ & $\begin{array}{c}23 \\
\text { DAT }\end{array}$ & $\begin{array}{c}25 \\
\text { DAT }\end{array}$ & $\begin{array}{c}28 \\
\text { DAT }\end{array}$ & $\begin{array}{c}32 \\
\text { DAT }\end{array}$ & $\begin{array}{c}45 \\
\text { DAT }\end{array}$ & $\begin{array}{c}60 \\
\text { DAT }\end{array}$ \\
\hline $\mathbf{T}_{1}$ & Pretilachlor@625 g a.i ha ${ }^{-1}$ as PE at 3 DAT & 83.1 & 76.8 & 95.4 & 107.3 & 148.1 & 155.0 & 178.2 & 197.7 & 217.8 & 201.7 \\
\hline $\mathbf{T}_{2}$ & Pyrazosulfuron ethyl @20 g a.i ha ${ }^{-1} 3$ DAT & 83.1 & 77.8 & 95.9 & 108.6 & 147.3 & 155.3 & 176.3 & 196.3 & 221.0 & 207.3 \\
\hline $\mathbf{T}_{3}$ & $\begin{array}{l}\text { Pretilachlor } 6 \%+\text { bensulfuron methyl } 0.6 \% @ 10 \mathrm{~kg} \\
\text { granules ha }{ }^{-1} \text { as PE at } 3 \text { DAT }\end{array}$ & 83.1 & 76.5 & 98.4 & 110.0 & 155.0 & 161.4 & 185.9 & 198.0 & 225.5 & 205.3 \\
\hline $\mathbf{T}_{4}$ & $\begin{array}{l}\text { Pyrazosulfuron ethyl @20 g a.i ha }{ }^{-1} \text { at } 3 \text { DAT } \\
\text { followed by } \\
\text { manual weeding at } 25 \text { DAT }\end{array}$ & 83.1 & 77.3 & 102.3 & 116.2 & 155.3 & 168.5 & 197.7 & 207.3 & 244.8 & 217.5 \\
\hline $\mathbf{T}_{5}$ & Penoxsulam@22.5 g a.i ha ${ }^{-1}$ as early PoE at 12 DAT & 83.1 & 86.4 & 108.9 & 99.0 & 119.6 & 126.2 & 157.4 & 172.9 & 225.7 & 203.3 \\
\hline $\mathbf{T}_{6}$ & $\begin{array}{l}\text { Cyhalofop-p-butyl @ } 100 \text { g a.i ha }{ }^{-1} \text { as early PoE } 12 \\
\text { DAT }\end{array}$ & 83.1 & 86.0 & 110.6 & 91.1 & 116.9 & 127.0 & 153.1 & 178.8 & 217.6 & 201.9 \\
\hline $\mathbf{T}_{7}$ & Bispyribac sodium @ $25 \mathrm{~g}$.i $\mathrm{ha}^{-1}$ as PoE 25 DAT & 83.1 & 88.2 & 109.0 & 127.7 & 171.5 & 192.0 & 157.6 & 163.4 & 219.9 & 201.0 \\
\hline$\overline{T_{8}}$ & Azimsulfuron@35 g a.i ha ${ }^{-1}$ as PoE at 25 DAT & 83.1 & 88.4 & 112.3 & 129.0 & 164.4 & 170.1 & 159.8 & 170.1 & 220.4 & 204.0 \\
\hline $\mathbf{T}_{9}$ & $\begin{array}{l}\text { Bispyribac sodium @ } 25 \mathrm{~g} \mathrm{a}^{\mathrm{i}} \mathrm{ha}^{-1}+\text { ethoxysulfuron } \\
18.75 \mathrm{~g}^{-1} \mathrm{ha}^{-1} \text { as PoE at } 25 \mathrm{DAT}\end{array}$ & 83.1 & 85.3 & 111.4 & 129.7 & 159.2 & 157.9 & 139.2 & 182.3 & 218.4 & 198.0 \\
\hline $\mathbf{T}_{10}$ & $\begin{array}{l}\text { Bispyribac sodium @ } 20 \mathrm{~g} \mathrm{a} . \mathrm{i} \mathrm{ha}^{-1}+\text { metsulfuron } \\
\text { methyl+ } \\
\text { chlorimuron ethyl @ } 4 \mathrm{~g} \mathrm{a.i} \mathrm{ha} \mathrm{h}^{-1} \text { as PoE at } 25 \mathrm{DAT}\end{array}$ & 83.1 & 85.9 & 109.7 & 130.7 & 170.0 & 184.5 & 153.9 & 194.9 & 237.3 & 206.0 \\
\hline $\mathrm{T}_{11}$ & $\begin{array}{l}\text { Pretilachlor@750 g a.i ha }{ }^{-1} \text { as PE at } 3 \text { DAT followed } \\
\text { by } \\
\text { ethoxysulfuron@18.75 g a.i ha }{ }^{-1} \text { as PoE at } 25 \text { DAT }\end{array}$ & 83.1 & 80.3 & 99.4 & 119.0 & 139.0 & 144.4 & 139.3 & 186.9 & 226.1 & 204.7 \\
\hline $\mathbf{T}_{12}$ & $\begin{array}{l}\text { Pretilachlor @ } 750 \mathrm{~g} \text { a.i ha }{ }^{-1} \text { as PE at } 3 \text { DAT followed } \\
\text { by } \\
\text { metsulfuron methyl + chlorimuron ethyl @ } 4 \text { g a.i ha }{ }^{-1} \\
\text { as PoE at } 25 \text { DAT }\end{array}$ & 83.1 & 79.7 & 98.6 & 115.2 & 141.2 & 142.9 & 123.1 & 193.6 & 234.7 & 203.0 \\
\hline$T_{13}$ & Hand weeding twice at 25 and 45 DAT & 83.1 & 90.7 & 115.9 & 132.1 & 181.2 & 200.0 & 210.6 & 220.2 & 233.8 & 207.3 \\
\hline $\mathbf{T}_{14}$ & Weedy check & 83.1 & 90.9 & 111.9 & 135.6 & 173.8 & 197.6 & 215.0 & 217.0 & 232.9 & 201.0 \\
\hline & $\mathrm{SEm} \pm$ & - & 1.8 & 2.4 & 4.0 & 7.7 & 8.7 & 13.5 & 8.5 & 10.1 & 6.6 \\
\hline & $\mathrm{CD}(\mathrm{P}=0.05)$ & - & 5.3 & 8.0 & 11.8 & 22.5 & 25.5 & 39.4 & 24.8 & 29.6 & 19.3 \\
\hline
\end{tabular}


Table.6 Activity of acid phosphatase ( $\mu \mathrm{g}$ of PNP released $\mathrm{g}^{-1}$ soil $^{-1}$ ) as influenced by weed management practices (2014)

\begin{tabular}{|c|c|c|c|c|c|c|c|c|c|c|c|}
\hline S.No & Treatments & $\begin{array}{c}0 \\
\text { DAT }\end{array}$ & $\begin{array}{c}6 \\
\text { DAT }\end{array}$ & $\begin{array}{c}12 \\
\text { DAT }\end{array}$ & $\begin{array}{c}15 \\
\text { DAT }\end{array}$ & $\begin{array}{c}23 \\
\text { DAT }\end{array}$ & $\begin{array}{c}25 \\
\text { DAT }\end{array}$ & $\begin{array}{c}28 \\
\text { DAT }\end{array}$ & $\begin{array}{c}32 \\
\text { DAT }\end{array}$ & $\begin{array}{c}45 \\
\text { DAT }\end{array}$ & $\begin{array}{l}60 \\
\text { DAT }\end{array}$ \\
\hline $\mathbf{T}_{1}$ & Pretilachlor@625 g a.i ha ${ }^{-1}$ as PE at 3 DAT & 71.6 & 63.5 & 76.6 & 89.9 & 104.2 & 114.7 & 137.3 & 167.0 & 190.8 & 179.1 \\
\hline $\mathbf{T}_{2}$ & Pyrazosulfuron ethyl @ $20 \mathrm{~g}$ a.i ha ${ }^{-1} 3$ DAT & 71.6 & 60.5 & 70.8 & 87.0 & 106.0 & 111.7 & 132.9 & 165.4 & 190.3 & 181.0 \\
\hline $\mathbf{T}_{3}$ & $\begin{array}{l}\text { Pretilachlor } 6 \%+\text { bensulfuron methyl } 0.6 \% @ 10 \mathrm{~kg} \\
\text { granules ha }{ }^{-1} \text { as PE at } 3 \text { DAT }\end{array}$ & 71.6 & 63.9 & 73.9 & 88.5 & 102.3 & 112.9 & 138.2 & 170.3 & 196.3 & 182.8 \\
\hline $\mathbf{T}_{4}$ & $\begin{array}{l}\text { Pyrazosulfuron ethyl @ } 20 \mathrm{~g} \text { a.i ha }{ }^{-1} \text { at } 3 \text { DAT } \\
\text { followed by } \\
\text { manual weeding at } 25 \mathrm{DAT}\end{array}$ & 71.6 & 63.6 & 72.8 & 87.4 & 109.2 & 115.3 & 134.7 & 175.2 & 202.1 & 197.7 \\
\hline $\mathbf{T}_{5}$ & Penoxsulam@22.5 g a.i ha ${ }^{-1}$ as early PoE at 12 DAT & 71.6 & 75.4 & 92.0 & 86.1 & 98.6 & 108.7 & 124.5 & 149.6 & 165.0 & 176.4 \\
\hline $\mathbf{T}_{6}$ & $\begin{array}{l}\text { Cyhalofop-p-butyl @ } 100 \mathrm{~g} \text { a.i ha }{ }^{-1} \text { as early PoE } 12 \\
\text { DAT }\end{array}$ & 71.6 & 79.7 & 92.1 & 84.6 & 97.6 & 108.3 & 125.3 & 150.3 & 175.4 & 176.0 \\
\hline $\mathbf{T}_{7}$ & Bispyribac sodium @ $25 \mathrm{~g} \mathrm{a.i} \mathrm{ha}{ }^{-1}$ as PoE 25 DAT & 71.6 & 76.4 & 89.9 & 103.8 & 121.9 & 127.4 & 118.4 & 131.4 & 166.7 & 177.5 \\
\hline $\mathbf{T}_{8}$ & Azimsulfuron@35 g a.i ha ${ }^{-1}$ as PoE at 25 DAT & 71.6 & 75.3 & 91.7 & 103.5 & 126.7 & 131.2 & 117.0 & 132.3 & 165.4 & 178.1 \\
\hline $\mathbf{T}_{9}$ & $\begin{array}{l}\text { Bispyribac sodium @ } 25 \mathrm{~g} \mathrm{a} . \mathrm{i} \mathrm{ha}^{-1}+\text { ethoxysulfuron } \\
18.75 \mathrm{~g} \mathrm{a.i} \mathrm{ha}^{-1} \text { as PoE at } 25 \mathrm{DAT}\end{array}$ & 71.6 & 74.2 & 94.4 & 102.5 & 121.4 & 126.8 & 120.0 & 137.1 & 176.3 & 178.9 \\
\hline $\mathbf{T}_{10}$ & 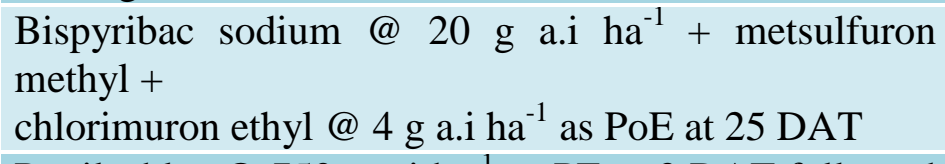 & 71.6 & 76.7 & 94.0 & 102.2 & 123.8 & 130.9 & 121.2 & 136.9 & 182.3 & 185.0 \\
\hline $\mathbf{T}_{11}$ & $\begin{array}{l}\text { Pretilachlor@750 g a.i ha }{ }^{-1} \text { as PE at } 3 \text { DAT followed } \\
\text { by } \\
\text { ethoxysulfuron@18.75 g a.i ha }{ }^{-1} \text { as PoE at } 25 \text { DAT }\end{array}$ & 71.6 & 64.6 & 73.9 & 87.7 & 106.3 & 115.6 & 121.3 & 139.3 & 174.7 & 178.6 \\
\hline $\mathbf{T}_{12}$ & $\begin{array}{l}\text { Pretilachlor @ } 750 \mathrm{~g} \text { a.i ha }{ }^{-1} \text { as PE at } 3 \text { DAT followed } \\
\text { by } \\
\text { metsulfuron methyl + chlorimuron ethyl @ } 4 \mathrm{~g} \mathrm{a.i} \mathrm{ha}^{-1} \\
\text { as PoE at } 25 \text { DAT }\end{array}$ & 71.6 & 66.4 & 76.4 & 89.7 & 107.5 & 115.5 & 117.9 & 137.9 & 165.2 & 177.2 \\
\hline $\mathbf{T}_{13}$ & Hand weeding twice at 25 and 45 DAT & 71.6 & 79.8 & 91.4 & 104.8 & 123.8 & 131.9 & 140.0 & 169.9 & 185.3 & 195.1 \\
\hline $\mathbf{T}_{14}$ & Weedy check & 71.6 & 78.6 & 91.9 & 103.4 & 121.6 & 127.8 & 135.8 & 167.6 & 180.5 & 195.9 \\
\hline & SEm \pm & - & 1.9 & 2.8 & 1.1 & 2.6 & 2.3 & 3.0 & 3.6 & 4.7 & 7.7 \\
\hline & $\mathrm{CD}(\mathrm{P}=0.05)$ & - & 5.6 & 7.5 & 3.1 & 7.7 & 6.6 & 8.7 & 10.5 & 18.7 & 22.5 \\
\hline
\end{tabular}


Table.7 Activity of alkaline phosphatase ( $\mu \mathrm{g}$ of PNP released $\mathrm{g}^{-1}$ soil $\mathrm{h}^{-1}$ ) as influenced by weed management practices (2013)

\begin{tabular}{|c|c|c|c|c|c|c|c|c|c|c|c|}
\hline S.No & Treatments & $\begin{array}{c}\mathbf{0} \\
\text { DAT }\end{array}$ & $\begin{array}{c}6 \\
\text { DAT }\end{array}$ & $\begin{array}{c}12 \\
\text { DAT }\end{array}$ & $\begin{array}{c}15 \\
\text { DAT }\end{array}$ & $\begin{array}{c}23 \\
\text { DAT }\end{array}$ & $\begin{array}{c}25 \\
\text { DAT }\end{array}$ & $\begin{array}{c}28 \\
\text { DAT }\end{array}$ & $\begin{array}{c}32 \\
\text { DAT }\end{array}$ & $\begin{array}{c}45 \\
\text { DAT }\end{array}$ & $\begin{array}{c}60 \\
\text { DAT }\end{array}$ \\
\hline$T_{1}$ & Pretilachlor@625 g a.i ha ${ }^{-1}$ as PE at 3 DAT & 51.2 & 43.1 & 75.5 & 86.0 & 145.6 & 156.2 & 164.8 & 186.8 & 196.3 & 166.3 \\
\hline $\mathbf{T}_{2}$ & Pyrazosulfuron ethyl @ $20 \mathrm{~g} \mathrm{a.i} \mathrm{ha}^{-1} 3$ DAT & 51.2 & 45.6 & 71.7 & 86.7 & 145.6 & 149.0 & 163.8 & 175.9 & 190.6 & 166.8 \\
\hline $\mathbf{T}_{3}$ & $\begin{array}{l}\text { Pretilachlor } 6 \%+\text { bensulfuron methyl } 0.6 \% @ 10 \mathrm{~kg} \\
\text { granules ha }{ }^{-1} \text { as PE at } 3 \text { DAT }\end{array}$ & 51.2 & 44.3 & 73.9 & 86.7 & 140.0 & 147.4 & 155.6 & 182.8 & 194.5 & 153.3 \\
\hline $\mathbf{T}_{4}$ & $\begin{array}{l}\text { Pyrazosulfuron ethyl @ } 20 \mathrm{~g} \text { a.i ha }{ }^{-1} \text { at } 3 \text { DAT } \\
\text { followed by } \\
\text { manual weeding at } 25 \text { DAT }\end{array}$ & 51.2 & 40.4 & 76.0 & 89.2 & 144.4 & 149.5 & 156.4 & 179.3 & 195.8 & 169.6 \\
\hline $\mathbf{T}_{5}$ & Penoxsulam@22.5 g a.i ha ${ }^{-1}$ as early PoE at 12 DAT & 51.2 & 53.0 & 101.9 & 89.4 & 132.2 & 138.9 & 144.5 & 170.3 & 186.3 & 151.4 \\
\hline $\mathbf{T}_{6}$ & $\begin{array}{l}\text { Cyhalofop-p-butyl @ } 100 \mathrm{~g} \text { a.i ha }{ }^{-1} \text { as early PoE } 12 \\
\text { DAT }\end{array}$ & 51.2 & 57.4 & 92.8 & 86.2 & 129.2 & 135.7 & 140.5 & 171.5 & 198.3 & 149.4 \\
\hline $\mathbf{T}_{7}$ & Bispyribac sodium @ $25 \mathrm{~g}$ a.i ha ${ }^{-1}$ as PoE 25 DAT & 51.2 & 57.1 & 99.8 & 103.1 & 135.6 & 145.2 & 132.7 & 148.7 & 180.2 & 157.5 \\
\hline$\overline{T_{8}}$ & Azimsulfuron@35 g a.i ha ${ }^{-1}$ as PoE at 25 DAT & 51.2 & 57.5 & 95.9 & 103.4 & 148.9 & 151.8 & 123.9 & 146.4 & 181.6 & 169.5 \\
\hline$T_{9}$ & $\begin{array}{l}\text { Bispyribac sodium @ } 25 \mathrm{~g}_{\text {a.i ha }}{ }^{-1}+\text { ethoxysulfuron } \\
18.75 \mathrm{~g}_{\text {a. }} \mathrm{ha}^{-1} \text { as PoE at } 25 \mathrm{DAT}\end{array}$ & 51.2 & 58.4 & 99.1 & 105.8 & 138.6 & 145.0 & 120.6 & 155.1 & 185.9 & 140.9 \\
\hline $\mathbf{T}_{10}$ & $\begin{array}{l}\text { Bispyribac sodium @ } 20 \mathrm{~g} \text { a.i } \mathrm{ha}^{-1}+\text { metsulfuron } \\
\text { methyl }+ \\
\text { chlorimuron ethyl @ } 4 \mathrm{~g} \text { a.i ha }{ }^{-1} \text { as PoE at } 25 \mathrm{DAT}\end{array}$ & 51.2 & 59.0 & 99.4 & 104.2 & 141.1 & 144.9 & 132.0 & 152.9 & 194.0 & 166.2 \\
\hline $\mathbf{T}_{11}$ & $\begin{array}{l}\text { Pretilachlor@750 g a.i ha }{ }^{-1} \text { as PE at } 3 \text { DAT followed } \\
\text { by } \\
\text { ethoxysulfuron@18.75 g a.i ha }{ }^{-1} \text { as PoE at } 25 \text { DAT }\end{array}$ & 51.2 & 42.5 & 78.9 & 88.2 & 144.4 & 145.2 & 124.6 & 143.8 & 180.1 & 155.3 \\
\hline $\mathbf{T}_{12}$ & $\begin{array}{l}\text { Pretilachlor @ } 750 \mathrm{~g} \text { a.i ha }{ }^{-1} \text { as PE at } 3 \text { DAT followed } \\
\text { by } \\
\text { metsulfuron methyl + chlorimuron ethyl @ } 4 \text { g a.i ha }{ }^{-1} \\
\text { as PoE at } 25 \text { DAT }\end{array}$ & 51.2 & 41.2 & 73.3 & 91.8 & 140.0 & 145.1 & 133.1 & 148.8 & 183.9 & 147.0 \\
\hline $\mathbf{T}_{13}$ & Hand weeding twice at 25 and 45 DAT & 51.2 & 60.6 & 102.5 & 105.8 & 138.9 & 145.6 & 149.6 & 153.9 & 181.8 & 166.4 \\
\hline $\mathbf{T}_{\mathbf{1 4}}$ & Weedy check & 51.2 & 59.3 & 101.1 & 107.6 & 135.6 & 141.3 & 144.8 & 155.7 & 187.9 & 149.5 \\
\hline & SEm \pm & - & 2.5 & 3.0 & 4.0 & 4.6 & 4.0 & 3.3 & 5.5 & 5.5 & 7.2 \\
\hline & $\mathrm{CD}(\mathrm{P}=0.05)$ & - & 7.2 & 9.6 & 11.7 & 13.5 & 11.8 & 9.6 & 16.2 & 16.0 & N.S. \\
\hline
\end{tabular}


Table.8 Activity of alkaline phosphatase ( $\mu \mathrm{g}$ of PNP released $\mathrm{g}^{-1}$ soil $^{-1}$ ) as influenced by weed management practices (2014)

\begin{tabular}{|c|c|c|c|c|c|c|c|c|c|c|c|}
\hline S.No & Treatments & $\begin{array}{c}0 \\
\text { DAT }\end{array}$ & $\begin{array}{c}6 \\
\text { DAT }\end{array}$ & $\begin{array}{c}12 \\
\text { DAT }\end{array}$ & $\begin{array}{c}15 \\
\text { DAT }\end{array}$ & $\begin{array}{c}23 \\
\text { DAT }\end{array}$ & $\begin{array}{c}25 \\
\text { DAT }\end{array}$ & $\begin{array}{c}28 \\
\text { DAT }\end{array}$ & $\begin{array}{c}32 \\
\text { DAT }\end{array}$ & $\begin{array}{l}45 \\
\text { DAT }\end{array}$ & $\begin{array}{c}60 \\
\text { DAT }\end{array}$ \\
\hline $\mathbf{T}_{1}$ & Pretilachlor@625 g a.i ha ${ }^{-1}$ as PE at 3 DAT & 50.8 & 47.2 & 68.9 & 78.4 & 98.5 & 123.9 & 144.0 & 171.3 & 186.8 & 163.4 \\
\hline $\mathbf{T}_{2}$ & Pyrazosulfuron ethyl @20 g a.i ha ${ }^{-1} 3$ DAT & 50.8 & 46.4 & 66.7 & 74.9 & 99.0 & 123.9 & 143.6 & 169.4 & 180.4 & 164.2 \\
\hline $\mathbf{T}_{3}$ & $\begin{array}{l}\text { Pretilachlor } 6 \%+\text { bensulfuron methyl } 0.6 \% @ 10 \mathrm{~kg} \\
\text { granules ha }{ }^{-1} \text { as PE at } 3 \text { DAT }\end{array}$ & 50.8 & 48.7 & 68.2 & 75.7 & 100.5 & 118.3 & 140.0 & 161.3 & 182.8 & 150.3 \\
\hline $\mathbf{T}_{4}$ & $\begin{array}{l}\text { Pyrazosulfuron ethyl @20 g a.i ha }{ }^{-1} \text { at } 3 \text { DAT } \\
\text { followed by } \\
\text { manual weeding at } 25 \text { DAT }\end{array}$ & 50.8 & 47.8 & 69.1 & 73.5 & 102.1 & 122.7 & 142.1 & 170.9 & 179.3 & 168.8 \\
\hline $\mathbf{T}_{5}$ & Penoxsulam@22.5 g a.i ha ${ }^{-1}$ as early PoE at 12 DAT & 50.8 & 55.4 & 94.8 & 81.7 & 92.6 & 110.9 & 132.1 & 172.3 & 177.3 & 146.4 \\
\hline $\mathrm{T}_{6}$ & $\begin{array}{l}\text { Cyhalofop-p-butyl @ } 100 \mathrm{~g} \text { a.i ha }{ }^{-1} \text { as early PoE } 12 \\
\text { DAT }\end{array}$ & 50.8 & 55.9 & 89.8 & 76.2 & 89.1 & 114.3 & 131.4 & 163.2 & 179.1 & 141.4 \\
\hline $\mathbf{T}_{7}$ & Bispyribac sodium @ $25 \mathrm{~g}$ a.i ha ${ }^{-1}$ as PoE 25 DAT & 50.8 & 54.8 & 92.4 & 98.6 & 104.1 & 120.9 & 102.2 & 155.3 & 181.6 & 159.7 \\
\hline $\mathbf{T}_{8}$ & Azimsulfuron@35 g a.i ha ${ }^{-1}$ as PoE at 25 DAT & 50.8 & 54.6 & 90.4 & 99.2 & 106.0 & 129.6 & 107.0 & 149.0 & 185.9 & 167.0 \\
\hline$\overline{T_{9}}$ & $\begin{array}{l}\text { Bispyribac sodium @ } 25 \mathrm{~g} \mathrm{a.i} \mathrm{ha}^{-1}+\text { ethoxysulfuron } \\
18.75 \mathrm{~g} \mathrm{a.i} \mathrm{ha}^{-1} \text { as PoE at } 25 \text { DAT }\end{array}$ & 50.8 & 56.9 & 93.0 & 103.8 & 107.8 & 119.2 & 102.7 & 134.5 & 191.7 & 150.4 \\
\hline $\mathbf{T}_{10}$ & $\begin{array}{l}\text { Bispyribac sodium @ } 20 \mathrm{~g} \text { a.i ha }{ }^{-1}+\text { metsulfuron } \\
\text { methyl + } \\
\text { chlorimuron ethyl @ } 4 \mathrm{~g} \text { a.i ha }{ }^{-1} \text { as PoE at } 25 \text { DAT }\end{array}$ & 50.8 & 58.4 & 92.0 & 106.8 & 102.8 & 121.8 & 104.6 & 148.5 & 180.1 & 160.9 \\
\hline $\mathbf{T}_{11}$ & $\begin{array}{l}\text { Pretilachlor@750 g a.i ha }{ }^{-1} \text { as PE at } 3 \text { DAT followed } \\
\text { by } \\
\text { ethoxysulfuron@18.75 g a.i ha }{ }^{-1} \text { as PoE at } 25 \text { DAT }\end{array}$ & 50.8 & 49.0 & 70.7 & 81.8 & 98.9 & 125.1 & 106.0 & 152.3 & 183.9 & 155.6 \\
\hline$T_{12}$ & $\begin{array}{l}\text { Pretilachlor @ } 750 \mathrm{~g} \text { a.i ha }{ }^{-1} \text { as PE at } 3 \text { DAT followed } \\
\text { by } \\
\text { metsulfuron methyl + chlorimuron ethyl @ } 4 \mathrm{~g} \mathrm{a.i} \mathrm{ha}^{-1} \\
\text { as PoE at } 25 \text { DAT }\end{array}$ & 50.8 & 47.9 & 65.7 & 81.1 & 99.4 & 120.7 & 103.8 & 144.7 & 181.8 & 150.0 \\
\hline$T_{13}$ & Hand weeding twice at 25 and 45 DAT & 50.8 & 59.6 & 93.9 & 101.5 & 106.3 & 119.6 & 143.4 & 165.7 & 187.9 & 161.9 \\
\hline $\mathbf{T}_{14}$ & Weedy check & 50.8 & 59.2 & 92.3 & 102.5 & 110.4 & 117.4 & 138.1 & 158.2 & 186.3 & 151.8 \\
\hline & $\mathrm{SEm} \pm$ & - & 1.5 & 1.8 & 3.1 & 3.9 & 4.3 & 2.2 & 4.8 & 4.9 & 5.8 \\
\hline & $\mathrm{CD}(\mathrm{P}=0.05)$ & - & 6.5 & 5.4 & 9.0 & 12.4 & 12.6 & 6.3 & 13.9 & 14.4 & N.S. \\
\hline
\end{tabular}




\section{Acid phosphatase activity}

The activity of acid phosphatase ( $\mu \mathrm{g}$ of PNP released $\mathrm{g}^{-1}$ soil $\mathrm{h}^{-1}$ ) as influenced by weed management practices is presented in Table 5 and 6 . A close perusal of data indicates that significant difference exists between herbicide treatments. In general acid phosphatase activity increased from 0 DAT to 45 DAT, thereafter the activity decreased.

At 6 DAT the higher acid phosphatase activity was recorded in weedy check $\mathrm{T}_{14}$ (90.9 and 78.6) which was on par with weed free by hand weeding at 25 and 45 DAT $\mathrm{T}_{13}$ (90.7 and 79.8) and rest of the treatments except in treatments where PE herbicide application was done with pretilachlor in $\mathrm{T}_{1}$, $\mathrm{T}_{11}$ and $\mathrm{T}_{12}$ and pretilachlor + bensulfuron methyl in $T_{3}$ and pyrazosulfuron ethyl in $T_{2}$ and $\mathrm{T}_{4}$ was done. The reduction in acid phosphatase activity was to a tune of $15 \%$ to $20 \%$ over control. In later stages the acid phosphatase activity increased and recorded on par results with control as crop reached 28 DAT during both the years.

In the same way early PoE herbicide treatments penoxsulam $\mathrm{T}_{5}$ (108.9 and 92.0) and cyhalofop p butyl $\mathrm{T}_{6}$ (110.6 and 92.1) when applied at 12 DAT resulted in sharp decrease in activity of acid phosphatase activity at 3 days after herbicide application (15 DAT) penoxsulam $\mathrm{T}_{5}$ (99.9 and 86.1) and cyhalofop p butyl $\mathrm{T}_{6}(91.1$ and 84.6 ) and there after it showed increasing trend and recorded on par results by 28 DAT $\mathrm{T}_{5}$ (157.4 and 124.5) and cyhalofop $p$ butyl $T_{6}$ (153.1 and 125.3) that of control during 2013 and 2014.

At 25 DAT, PoE herbicides application with azimsulfuron $\left(\mathrm{T}_{8}\right)$, ethoxysulfuron $\left(\mathrm{T}_{9}\right.$ and $\mathrm{T}_{11}$ ), metsulfuron methyl + chlorimuron ethyl $\left(\mathrm{T}_{10}\right.$ and $\left.\mathrm{T}_{12}\right)$ and bispyribac sodium $\left(\mathrm{T}_{7}, \mathrm{~T}_{9}\right.$ and $\mathrm{T}_{10}$ ) was done. Treatment imposed plots showed decrease in acid phosphatase activity from 3 days after herbicide application (28 DAT) and thereafter significantly increased at later stages by 45 DAT recording higher acid phosphatase activity in treatment pyrazosulfuron ethyl $20 \mathrm{~g}$ a.i.ha ${ }^{-1}$ followed by manual weeding at $25 \mathrm{DAT}\left(\mathrm{T}_{4}\right)$ which was at par with rest of the treatments. Later at 60 DAT there was decrease in acid phosphates activity in all the plots.

The herbicide treatments were found to have an antagonistic effect on acid phosphatase activity soon after (3 days after herbicide application) in the present study due to disturbed biological equilibrium in soil. But in later stages increase in phosphatase activity might be due to increase in phosphate stabilizer population, degradation of applied herbicide or weeds that were killed by herbicides might have served as a carbon source and the results are agreement with works of (Kavitha et al., 2011).

\section{Alkaline phosphates activity}

The activity of alkaline phosphatase ( $\mu \mathrm{g}$ of PNP released $\mathrm{g}^{-1}$ soil $\mathrm{h}^{-1}$ ) as influenced by herbicide treatments is presented in Table 7 and 8. A close perusal of data indicates that significant difference exists between herbicide treatments. Alkaline phosphatase activity increased from 0 DAT to 45 DAT, thereafter the activity decreased.

At 6 DAT the higher alkaline phosphate activity was recorded in $\mathrm{T}_{13}$ hand weeding twice at 25 and 45 DAT (60.6 and 59.6) during 2013 and 2014 respectively, which was on par with rest of the treatments, except in treatments where PE herbicide application was done with pretilachlor in $\mathrm{T}_{1}$ (43.1 and 47.2), $\mathrm{T}_{11}$ (42.5 and 49.0), $\mathrm{T}_{12}$ (41.2 and 47.9), pyrazosulfuron ethyl in $\mathrm{T}_{2}$ (45.6 and 46.2), $\mathrm{T}_{4}$ (40.4 and 47.8) and $\mathrm{T}_{3}$ pretilachlor + bensulfuron methyl (44.3 and 47.8) during 2013 and 2014 respectively. With the 
progress of time by $23 \mathrm{DAT}$, the PE herbicide treated plots recorded on par results with weedy check (control). Thereafter herbicide treated plots recorded significantly higher urease activity than control during both the years of study.

In the same way early PoE herbicide treatments penoxsulam $\mathrm{T}_{5}$ (101.9 and 94.8) and cyhalofop $\mathrm{p}$ butyl $\mathrm{T}_{6}$ (92.8 and 89.8) when applied at 12 DAT resulted in sharp decrease in activity of alkaline phosphatase activity at 3 days after herbicide application (15 DAT) both in penoxsulam $\mathrm{T}_{5}$ (89.4 and 81.7) and cyhalofop $\mathrm{p}$ butyl $\mathrm{T}_{6}(86.2$ and 76.2) and there after it showed increasing trend and recorded on par results by 28 DAT $\mathrm{T}_{5}$ (144.5 and 132.1) and cyhalofop $\mathrm{p}$ butyl $\mathrm{T}_{6}$ (140.5 and 131.4) that of control during 2013 and 2014. Thereafter higher values than control were recorded till 45 DAT. From 60 DAT alkaline phosphates activity decreased insignificantly. At 25 DAT PoE treatments imposition with herbicides azimsulfuron $\left(\mathrm{T}_{8}\right)$, ethoxysulfuron ( $\mathrm{T}_{9}$ and $\left.\mathrm{T}_{11}\right)$, metsulfuron methyl + chlorimuron ethyl $\left(\mathrm{T}_{10}\right.$ and $\left.\mathrm{T}_{12}\right)$ and bispyribac sodium $\left(\mathrm{T}_{7}, \mathrm{~T}_{9}\right.$ and $\left.\mathrm{T}_{10}\right)$ was done.

Treatment imposition resulted in decrease in alkaline phosphatase activity from 3 days after herbicide application (28 DAT) and then significantly increased at later stages by 45 DAT. From 60 DAT there was decrease in alkaline phosphatase activity in all the plots.

Initial decrease in enzymatic activity could be due to the fact that alkaline phosphatase is of extracellular origin and the death of some microorganisms could cause a reduction in the production of excretion of enzymes leading to a reduction in the soil activity (Perucci et al., 1999). It was observed in this experiment that the inhibitory effect of herbicides on enzyme activities is short lived and decreased with time. Recovery of enzyme activities after initial inhibition could be due to growth of microbial population after adaptation or most probably due to increased availability of nutrients due to degradation of herbicides (Ismail et al., 1998).

Mariora et al., (2015) reported that metsulfuron methyl greatly inhibited dehydrogenase activity. Urease and dehydrogenase activity can be either stimulated or inhibited by herbicide application depending on the herbicide type and exposure dose. Moreover dehydrogenase activity proved to be an important indicator of side effects that are associated with the use of sulfonyl urea herbicides (Pampulha and oliveira, 2006). Singh (2014) at Aligarh reported that dehydrogenase was negatively correlated to the herbicide concentrations of pretilachlor at 500, 1000 and $1500 \mathrm{~g}$ a.i. ha ${ }^{-1}$ Herbicides persistence in the soil is expressed as half-life or time required to degrade fifty percent of the original molecule as reported by Sondhia (2014) is pretilachlor 10-11 days, sulfosulfuron 3-27, metsulfuron methyl 147170 days, chlorimuron 60 days and pyrazosulfuron 16-21. Mayeetreyee et al., (2013) reported that the effects of herbicides are highly transitory; it is particularly difficult to explain a change of soil enzyme activities in response to certain factors or to establish the cause-effect relationships between the herbicide treatments and the various components contributing to the variation in overall soil enzyme activities. Further the data suggested that the detracting effect of herbicides towards soil microbial populations and enzyme activities decreased with time. The urease activity in butachlor treated soil showed an increasing trend from 7 th day $\left(5.68 \pm 0.023 \mu \mathrm{g} \mathrm{NH}^{+} \mathrm{g}^{-1}\right.$ soil hr$\left.{ }^{-1}\right)$ to 28 th day $\left(9.741 \pm 0.035 \mu \mathrm{g} \mathrm{NH} 4^{+} \mathrm{g}^{-1}\right.$ soil $\left.\mathrm{hr}^{-1}\right)$ of incubation. Similar trend was exhibited in pyrazosulfuron, paraquat and glyphosate treated soil, which varies from $(6.2 \pm 0.034$ to $8.4 \pm 0.043) \mu \mathrm{g} \mathrm{NH} 4^{+} \mathrm{g}^{-1}$ soil hr${ }^{-1},(3.8 \pm$ 0.013 to $6.4 \pm 0.024) \mu \mathrm{g} \mathrm{NH} 4^{+} \mathrm{g}^{-1}$ soil $\mathrm{hr}^{-1}$ 
and $(4.2 \pm 0.025$ to $6.9 \pm 0.038) \mu \mathrm{g} \mathrm{NH} 4+\mathrm{g}^{-1}$ soil $\mathrm{hr}^{-1}$ respectively. The soil dehydrogenase activity showed an increasing trend from $7^{\text {th }}$ to $28^{\text {th }}$ day of incubation in case of all herbicide treated soil viz., pyrazosulfuron, paraquat and glyphosate treated soil, which varies from $\left[\left(1.187 \pm 0.042 \mu \mathrm{g}\right.\right.$ TPF $\mathrm{g}^{-1}$ soil $\left.\mathrm{hr}^{-1}\right)$ to $\left(12.15 \pm 0.916 \mu \mathrm{g}_{\text {TPF }} \mathrm{g}^{-1}\right.$ soil $\left.\left.\mathrm{hr}^{-1}\right)\right]$, soil treated with pyrazosulfuron had the lower set of dehydrogenase activities. Meena et al., (2013) at Varanasi revealed that under field conditions, urease activity was higher at panicle initiation stages but under greenhouse conditions the activity was more pronounced at tillering stages. Low activity at the grain filling could be related to lower microbial biomass. The correlation between urease and organic carbon at panicle and harvest $(\mathrm{r}=$ $0.96^{* *}$ and $\mathrm{r}=0.87^{* *}$, respectively) and available nitrogen $(\mathrm{r}=0.94 * *$ and $\mathrm{r}=0.91 * *$, respectively).Herbicides are extraneous to soil component pools, and are expected to affect the catalytic efficiency, behavior of soil enzymes (Sannino and Gianfreda, 2001), which contribute to the total biological activity of the soil plant environment under different states (Dick, 1997). Various studies have revealed that the herbicides can cause qualitative and quantitative change in enzyme activity (Xia et al., 2012). Vandana et al., (2012) reported that there was an increase in soil enzyme activity from 0 to 60 days after transplanting of the crop irrespective of the treatment of the soil with butachlor or cyhalofop $\mathrm{p}$ butyl. The increase with age of the crop, however, was less during the first two stages of the crop and with significant increase at later stages. Urease activity ( $\mu \mathrm{g}$ of $\mathrm{NH}^{+}$released $\mathrm{g}^{-1}$ soil $\mathrm{h}^{-1}$ ) in control increased from 0 DAT (1.9) to 60 DAT (3.9). Thereafter, the activity decreased to almost 0 day level at 105 DAT. At 45 DAT, butachlor showed significantly higher Urease activity (6.9) followed by Cyhalofop-butyl (5.6), farmer's practice (3.9) and control (3.8). At 60 DAT, Butachlor recorded the higher activity (8.1) followed by cyhalofop-butyl (7.8), farmer's practice (4.5) and control (3.9). Kavitha et al., (2011) reported that the enzyme activity inhibition followed a trend, butachlor> 2, 4-D > pretilachlor> pyrazosulfuron. Soil enzyme activities can be used as early and sensitive indicators of management induced changes in soil and soil microbial activity Nannipieri (1994). Natural and anthropogenic factors may affect the soil enzyme activities directly or indirectly (Gianfreda and Bollag, 1996). Among anthropogenic factors, herbicides are one of the major groups of pesticides. A number of herbicides have not only been introduced as pre or post emergence weed killer (Ayansina and Oso, 2006) but also leave unwanted residues in soil, which are ecologically harmful (Derksen et al., 2002). Preferred herbicides should not only have good efficacy, but also poses minimum adverse effects to crop, ecology and environment (Riaz et al., 2007). Benton et al., (2007) revealed that dehydrogenase activity is generally used as an index of metabolic activity of the microbial population in soil. Except a slight depression initially, butachlor at field rate was generally non inhibitory in its effect on dehydrogenase activity in rice on a vertisol. Dehydrogenase activity in soil, the order was pretilachlor $>$ alachlor $>$ butachlor, whereas in case of urease activity, the order changed to pretilachlor $>$ butachlor $>$ alachlor. The soil half-lives of alachlor, butachlor and pretilachlor were 9.3, 12.7 and 7.3 days respectively, which could be accounted for in terms of their respective chemical structures, as well as variable adsorption, degradation, differential effects of the agents on soil microbes (Shen et al., 2005). Zheng et al., (2005) reported that soil urease activity ascended gradually with rice growth at early stage and reached the higher value on the 30 DAT and then decreased, while acid phosphatase and dehydrogenase activities descended before ascended and then 
descended again. Soil urease activity and acid phosphatase activity showed a peak value at the tillering stage about 30 DAT, but the peak value of dehydrogenase activity emerged at about 50 DAT and the three soil enzymatic activities were significantly different at the different developmental stages. The evaluation of soil enzyme activities may provide useful information on microbial activity and be helpful in establishing the effects of soil specific environmental conditions. An alternation in soil microorganisms, their number, activity and diversity may serve as indicators of soil fertility and reflect the soil quality (Schloter et al., 2003). The enzyme activities are considered to be sensitive to chemical agrochemicals and have been proposed as potential indicators for measuring the degree of pollution of contaminated soil (Kuperman and Margret, 1997) and referred to as markers of soil environmental purity (Aon and Colaneri, 2001). Glyphosate and paraquat have been reported to cause activation in soil urease and invertase soil enzymes (Sannino and Gianfreda, 2001). Herbicide treatment resulted in a significant drop in dehydrogenase activity whencompared to the control soil samples. soils treated with prime extra had the lower dehydrogenase activity of $16.09 \mu \mathrm{g}\left(\mathrm{g}^{-1} \mathrm{~min}^{-1}\right)$ after the sixth week of treatment, while soils treated with glyphosate had the higher dehydrogenase activity of $20.16 \mu \mathrm{g}\left(\mathrm{g}^{-1} \mathrm{~min}^{-1}\right)$. From the above research it can be concluded that Detracting effect of herbicides towards enzyme activities decreased with time. Except a slight depression initially the tested herbicides at field rate was non-inhibitory for prolonged period.

\section{Acknowledgment}

I profusely thank to Prof. Jayashankar Telangana State Agricultural University for providing me opportunity to work on this.

\section{References}

Aon, M.A. and Colaneri, A.C. 2001. Temporal and spatial evolution of enzymatic Activities and physicchemical properties in an agricultural soil. Applied Soil Ecology. 18: 255.

Ayansina, A.D.V. and Oso B.A. 2006. Effect of two commonly used herbicides on soil microflora at two different concentrations, African Journal of Biotechnology. 5(2): 129- 132.

Benton, T.G., Solan, M., Travis, J.J. and Sait, S.M. 2007. Microcosm experiments can inform global ecological problems. Trends in Ecology and Evolution. 22:516-521.

Bollen, W. B. 1961. Interactions between pesticides and soil micro-organisms. Review Microbiology. 15: 69.

Bowles T.M., Acosta-Martínez V., Calderón F., Jackson L.E. 2014.Soil enzyme activities, microbial communities, and carbon and nitrogen availability in organic agroecosystems across an intensively-managed agricultural landscape. Soil Biology and Biochemistry. 68: 252-262.

Casida, L.E. 1964. Microbial metabolic activity in soil as measured by dehydrogenase determinations. Applied and Environmental Microbiology. 6 (34): 630-636.

Derksen D.A., Anderson, R.L., Blackshaw, R.E. and Maxwell, B. 2002. Weed dynamics and management strategies for cropping systems in the Northern Great Plains, Agronomy Journal. 94 174-185.

Dick R., 1997. Soil enzyme activities as integrative indicators of soil health. Pesticides research Journal. 20(3):216221.

Eivazi, F and Tabatabai, M.A. 1977. Alkaline and acid phosphatases activity in 
soils.Soil Biology and Biochemistry. 9 (3): 167-172.

Gianfreda L. and Bollang, J.1996. Influence of natural and anthropogenic factors on enzyme activity in soil. In Soil Biochemistry. Marcel Dekker, New York 1087-1089.

Ismail, B.S., Yapp, K.F. and Omar, O. 1998. Effects of metasulfuron-methyl on amylase, urease and protease. Indian Journal of Weed Science. 36 (1): 210213.

Kavitha, M. P, Ganesaraja, V, Paulpandi, V.K and BalaSubramania, R 2011. Rhizosphere enzyme activities as influenced by age of seedlings, Weed management practices and humic acid application under system of rice intensification. Indian Journal of agricultural research. 45(2): 151-155.

Kuperman, R.G., Margaret, M.C. 1997. Soil heavy metal concentration microbial biomass and enzyme activity in a contaminated grassland ecosystem. Soil Biology and Biochemistry. 29: 179-190.

Latha P.C., Gopal, H. 2010. Effect of herbicides on soil microorganisms. Indian Journal of WeedScience. 42(3 \& 4): 217-222.

Marioara, N. F. Sorin, O. and Voia, E. 2015. The effect of some insecticides on soil microorganisms based on enzymatic and bacteriological analyses. Romanian Biotechnological Letters, 20 (3) 1043910447.

Mayeetreyee, B., Mamata, P., Alka, S., Monty, K., Jitesh, K. and Amiya, K. 2013. Effect of four herbicides on soil organic carbon, microbial biomass-c, enzyme activity and microbial populations in agricultural soil. International Journal of Research in Environmental Science and Technology. 3(4): 100-112.

Meena V. S., Maurya, B. R. Verma, R. Meena1, R. S., Jatav, G. K. and S. K.
Meena 2013. Soil microbial population and selected enzyme activities as influenced by concentrate manure and inorganic fertilizer in alluvium soil of Varanasi. The Bioscan. 8(3): 931-935.

Nannipieri, P., 1994. The potential use of soil enzymes as indicators of productivity, sustainability and pollution, Management in Sustainable Farming System, CSIRO, Melbourne.

Nannipieri, P., Ascher J., Ceccherini, M.T., Landi, L., Pietramellara, G. and Renella, G. 2003. Microbial diversity and soil functions. European Journal of Soil Science, 54: 655-670.

Pampulha, M.E. and Oliveira, A. 2006. Impact of a herbicide combination of bromoxynil and prosulfuron on soil microorganisms. Current Microbiology. 53: 238-243.

Perucci, P., Dumontet, S., Bufo, S.A., and Mazzatur, C. 2000. Effects of organic amendment and herbicide treatment on soil microbial biomass. Biology of Fertile Soils. 32:17-20.

Perucci, P.C., Vischetti, F. and Battistoni, E. 1999. Rimsulfuron in a silt clay loam soil: Effects upon microbiological and biochemical properties under varying microcosm conditions, Soil Biology and Biochemistry. 31: 195-204.

Rao, P.C and Raman, S. 1998. Effect of herbicides on soil dehydrogenase activity in flooded rice soil. Journal Indian Society Soil Science. 46(3): 470471.

Riaz, M.M., Jamil, T.Z. and Mahmood, M. 2007. Yield and yield components of maize as affected by various Weed control methods under rain-fed conditions of Pakistan. International Journal of Agricultural Biology. 9: 152155.

Sannino, F., Gianfreda, L. 2001. Pesticide influence on soil enzymatic activities. Chemosphere. 45: 417- 425. 
Schloter M., Dilly, O. and Munch, J. 2003. Indicators for evaluating soil quality, Agriculture Ecosystem Environment. 98: 255-262.

Sebiomo, A., Ogundero, V. W. and Bankole, S. A. 2011. Effect of four herbicides on microbial population, soil organic matter and dehydrogenase activity. African Journal of Biotechnology. 10(5): 770-778.

Shen, G.Q., Cao, L.K. Lu, Y.T. and Hong, J.B. 2005. Influence of phenanthrene on cadmium toxicity to soil enzymes and microbial growth. Environmental Science Pollution Research. 12: 259263.

Singh, R. 2014. Influence of Pendimethalin Application with Different Fertilizers on Soil Enzyme Activities in Bulandshahr soil. International Journal of Scientific and Research Publications. 4 (5): 1-6.

Sondhia, S 2014. Herbicides residues in soil, water, plants and non-targeted organisms and human health implications: an Indian perspective. Indian Journal of Weed Science. 46(91): 66-85.

Tabatabai, M.A and Bremner, J. 1969. Use of P-nitro phenyl phosphate for assay of soil phosphatase activity. Soil Biology and Biochemistry. 1: 301-307.

Vandana, L.J., Rao, P.C. and Padmaja, G. 2012. Effect of herbicides and nutrient management on soil enzyme activity. Journal of Rice Research. 5 1-2.

Xia X., Zhao, H. M. and Wang, H. M., 2012. Influence of butachlor on soil enzymes and microbial growth. Journal of Food Agriculture Environment. 9(2):753-756.

Zheng, Y., Chen, S. and Liu, D. 2005. Sorts and characteristics of microorganisms capable of biodegrading pesticides in soil. Journal of Huanggang Normal University. 10: 169-173.

\section{How to cite this article:}

Spandana Bhatt, P., M. Yakadri, Subashreddy, M. Madhavi, S. Sridevi and Leela Rani. 2018. Rhizosphere Enzyme Activities as Influenced Chemical Weed Management Practices in the Transplanted Rice. Int.J.Curr.Microbiol.App.Sci. 7(05): 1728-1746. doi: https://doi.org/10.20546/ijcmas.2018.705.202 